\title{
Synthesis and applications of calcium-aluminum layered double hydroxides - an overview*
}

\author{
Ira Wahadah Md Ghazali'1), Farah Liyana Bohari ${ }^{1)}$ (ORCID ID: 0000-0003-3282-1471), \\ Nur Nadia Dzulkifli') ${ }^{10000-0003-3451-9719), ~ A s i a h ~ A b d u l l a h ~}{ }^{1)}$ (0000-0002-9409-1649), Is Fatimah ${ }^{2)}$ (0000-0001-5551-6563), \\ Sheikh Ahmad Izaddin Sheikh Mohd Ghazali ${ }^{1), * *)}(0000-0002-7176-6711)$
}

DOI: dx.doi.org/10.14314/polimery.2021.10.2

\begin{abstract}
The synthesis and application of layered calcium-aluminum double hydroxides (Ca-Al LDHs) for the encapsulation of organic anions is discussed. The mechanism of the encapsulation process was explained. These types of compounds have great potential and can be used in targeted therapies, including in drug dosing systems.
\end{abstract}

Keywords: layered double hydroxides, process was explained, nanotechnology.

\section{Synteza i zastosowanie warstwowych podwójnych wodorotlenków wapniowo-glinowych - przegląd literatury}

\begin{abstract}
Streszczenie: Omówiono syntezę i zastosowanie warstwowych podwójnych wodorotlenków wapniowo-glinowych (Ca-Al LDHs) do kapsułkowania anionów organicznych. Wyjaśniono mechanizm procesu kapsułkowania. Tego typu związki mają bardzo duży potencjał i mogą znaleźć zastosowanie w terapiach celowych m.in. w systemach kontrolowanego dozowania leków.
\end{abstract}

Słowa kluczowe: warstwowe podwójne wodorotlenki, proces kapsułkowania, nanotechnologia.

Nanocomposites are defined as high production materials that have uncommon combinations of properties with their unique designs. Nanocomposites are multiphase solid materials with a repeated distance in nanometer range between the phases. Additionally, they cover a significant variety of systems such as one-dimensional (1D), two-dimensional (2D), three-dimensional (3D), and amorphous materials [1]. Moreover, nanocomposite polymeric materials became the more suitable alternatives and are able to overcome the limitations of microcomposites as they are better prepared for any challenges concerning stoichiometry in the nanocluster phase. Nanocomposites differ in terms of their mechanical, thermal, optical, catalytic, and other properties from the component materials. These properties are also considered on the interfacial characteristics and their morphology [2].

\footnotetext{
1) Faculty of Applied Sciences, Universti Teknologi MARA Cawangan Negeri Sembilan Kampus Kuala Pilah, Kuala Pilah 72000, Negeri Sembilan, Malaysia.

2) Department of Chemistry, Faculty of Mathematics and Natural Sciences, Universitas Islam Indonesia, Kampus Terpadu UII, Jl. Kaliurang Km 14, Sleman, Yogyakarta 55584, Indonesia.

*) Material contained in this article was presented at the $1^{\text {st }} \mathrm{Ma}$ laysia International Conference on Nanotechnology \& Catalysis (MICNC 2021), 1-3 September 2021, Malaya, Malaysia.

**) Author for correspondence:

sheikhahmadizaddin@uitm.edu.my
}

Layered double hydroxides (LDHs) are among the most favorable 2D nanocomposites and have secured significant attention from researchers, particularly in biomedical sectors. LDH nanocomposites are also known as the anionic clays or hydrotalcite-like materials. In general, the structure of the 2D material is composed of cationic metal atoms as the inner layer sandwiched between two intercalated anionic hydroxide layers [3]. Anionic drugs, such as salsalate, have been used for drug deliveries through the exchange with the anionic interlayers due to the presence of the cationic metals. LDHs have several significant advantages and among the most favored are the great number of plausible compositions and the combinations of metal-anion that can be synthesized. Moreover, LDH has distinctive features such as high chemical stability, $\mathrm{pH}$-dependent solubility, and good biocompatibility [4].

Additionally, LDHs are favored in the production of biocompatible inorganic lamellar nanomaterials due to their numerous appealing features such as high surfaceto-volume ratio, potential ability to accumulate specific molecules and timely release to targets [5]. Because of their unique properties, LDHs have been employed in innumerable applications including additives in polymers and agriculture, pollution removal through the absorption process of organic wastes and heavy metal ions [3], and nanocarriers in drug delivery systems in pharmaceutics [6]. LDHs in pharmaceutics play a great role in healthcare, because numerous pharmaceutical 
drugs could be intercalated between the hydroxide layers using its ionic exchange capacity. Consequently, the treatment for numerous fatal diseases has been revolutionized by the usage of novel nano drugs or smart drugs.

Intercalation is defined as the process of inserting guest molecules or ions into lattices that act as hosts through either chemical or thermally reversible reactions. Intercalation reactions involve the absorption, exchange, or insertion of guest species to host surfaces. Intercalation compounds or the guest-hosts have slightly unsettled structures compared to the host structures. Intercalation is also known as the insertion, inclusion, or topotactic reaction [7]. An intercalation process is reversible and mostly takes place near atmospheric temperature. However, for the reactions to happen, the temperature should be high enough, approximately at $120^{\circ} \mathrm{C}$ [8] to confirm the movability of the guest species. Temperatures over $120^{\circ} \mathrm{C}$ might break the bonds in the lattices resulting in the rearrangement of the host lattices structures [9]. The critical factors that determine the success of intercalation or separation of layers are the dimensions and the functional groups of the guest molecules, the anions size, and the interactions of the negatively-charged anions with the positively-charged host [9]. Figure 1 shows the intercalation process that occurred between an $\mathrm{LDH}$ and its interest anions [10].

In this review, studies since 2002 on how to synthesize LDHs, the structure of LDHs, the intercalation process for numerous types of drugs in different LDHs hosts, and their controlled release process were collected and studied. This review aims to report and examine the latest development in LDH nanoparticles as an efficient drug delivery system. Consequently, the review provides an outlook on possible progress to be made and future challenges that might be encountered.

\section{BACKGROUND OF LAYERED DOUBLE HYDROXIDES}

Very good properties and distinguishing performance of nanomaterials have captured significant attention and applications of nanomaterials are widespread. For instance, in the electrochemical field, the unique characteristics that nanomaterials possess including large surface area and excellent physical, chemical, mechanical, and electrical properties are desirable. The large surface area of nanocomposites plays a dynamic role in enhancing the kinetics of electrochemical reactions by providing a great number of active sites. Additionally, selectivity towards target analytes could be achieved by further functionalizing the nanocomposites with desired chemical moieties [11].

LDHs are layered crystalline materials that have the significant potential of being nanofillers for polymers because they permit easy interlayer exchanges of ionic species. This property was demonstrated in thousands of studies over the years, where the anionic clay materials were successfully dispersed in a wide range of nanoscale matrices after a suitable organic modification [12].

\section{STRUCTURE OF LAYERED DOUBLE HYDROXIDES}

Naturally formed LDHs were found in 1842 in Sweden. The double-sheet structures were formed by a reaction between bases and diluted solutions of metals. The first LDH structures were synthesized by W. Feithnecht, a German scientist, in 1942 [13]. The LDHs from the synthesis conformed to a general formula of:

$$
\left[\mathrm{M}(\mathrm{II}) 1-\mathrm{x} \mathrm{M}(\mathrm{III}) \mathrm{x}(\mathrm{OH})_{2}\right]+[\mathrm{An}-\mathrm{x}] \cdot \mathrm{yH}_{2} \mathrm{O}
$$

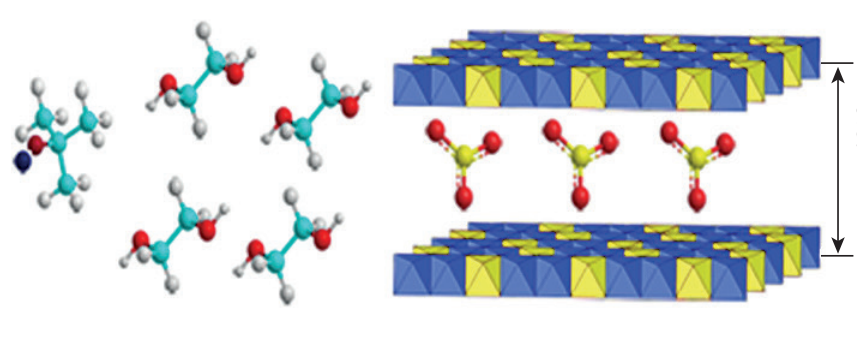

Nitrate

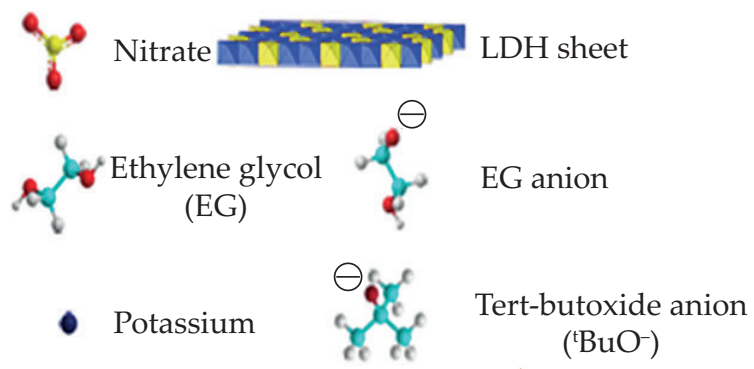

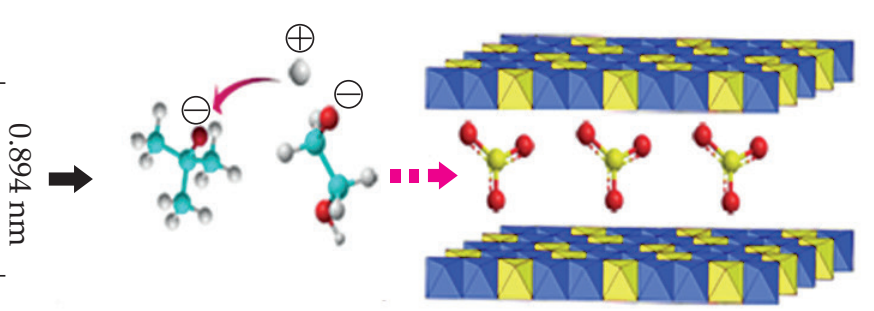

Capture proton from $\mathrm{EG}$ by ${ }^{\mathrm{t}} \mathrm{BuO}^{-}$

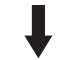

Exchange $\mathrm{NO}_{3}^{-}$by EG anion

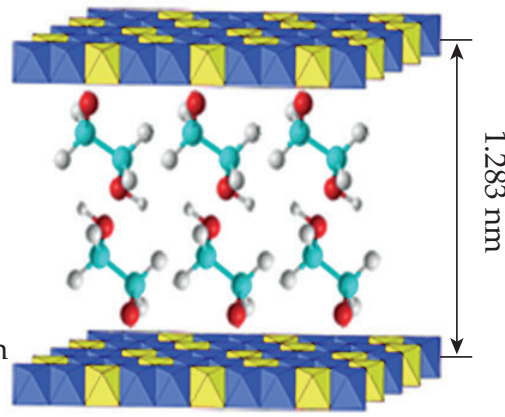

Fig. 1. Schematic diagram of ethylene glycol (EG) intercalation into a Mg-Al LDH [10] 
where: $M($ II) and $M($ III) were divalent and trivalent metal cations, respectively and n- was n-valent anion.

The early LDHs had layered crystal structures with large variations that depended on the nature of the cations, $\mathrm{M}(\mathrm{II})$ to $\mathrm{M}(\mathrm{III})$ molar ratio, and the type of used anions. The reported suitable range for the synthesis of the LDH compounds was $0.2 \leq x \leq 0.33$. For example, the ratio of $\mathrm{M}^{2+} / \mathrm{M}^{3+}$ was between 2:1 and 4:1 [4].

LDHs resemble brucite, $\mathrm{Mg}(\mathrm{OH})_{2}$ where in brucite, the $\mathrm{Mg}^{2+}$ is bound to six $\mathrm{OH}-$ ions, resulting in the octahedral structure that is connected, thus forming an infinite 2D layer. The brucite layers are positively-charged because the trivalent ions were replaced with divalent ions, and the positive charge of the interlayer spaces is then balanced by the localized anions. To stabilize the resulting $\mathrm{LDH}$ structures, water molecules are interleaved in the interlayer spaces. The positively-charged brucite types are octahedral sheets that alternate with carbonate anions interlayers. The carbonate anions are arranged with water molecules. The structure of the LDH is illustrated in Figure 2 [11].

The size or the ratio of the anions charges were shown as vital factors in LDHs formation. Large-sized anions contained low charges and were not able to stabilize homogenously between the positively-charged layers. Therefore, the host-guest relationship was compulsory between the host inorganic layers and the dimension of the guests in the interlayers [4].

For ages, LDHs or hydrotalcite-like materials were derived from hydroxy carbonates like calcium, magnesium, and zinc. The unique properties of LDH nanoparticles allowed them to have a controlled release system of intercalated species within targeted cells. One of their unique properties is the ability to remain stable under basic conditions but break at lower $\mathrm{pH}$ levels in a cell's

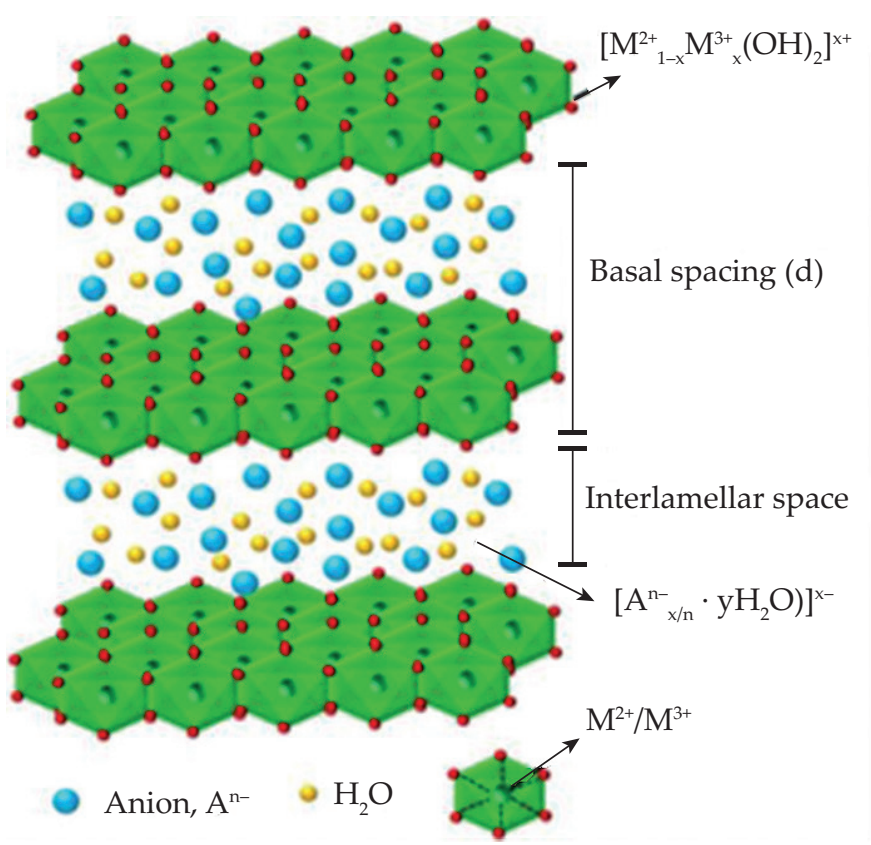

Fig. 2. An illustration of the first synthesized LDH structure [4] lysosome. There are numerous types of LDHs used in nanomaterial applications. The best known LDHs are Zn-Al LDHs, Mg-Al LDHs, and Ca-Al LDHs. These LDHs are comprised of two metal cations, a trivalent cation, and a monovalent or a divalent cation [14]. However, among these LDHs, Zn-Al LDH and Mg-Al LDH are the most studied around the world and there are hundreds of documented reports regarding their synthesis, characterizations, and the results in drug delivery systems compared to Ca-Al LDHs [15].

\section{Synthesis of layered double hydroxides}

\section{Co-precipitation method}

The co-precipitation technique is the most commonly applied in the production of LDHs from aqueous solutions that contain divalent, $\mathrm{M}(\mathrm{II})$, and trivalent, $\mathrm{M}(\mathrm{III})$, metal cations with various compositions, and the addition of aqueous sodium hydroxide $(\mathrm{NaOH})$ as bases. The process is also known as simultaneous precipitation of $\mathrm{MII}(\mathrm{OH})_{2}$ and $\mathrm{MII}(\mathrm{OH})_{3}$ in a super-concentrated solution. The products obtained from the method are finite crystallites with a large particle size distribution [17]. The co-precipitation technique used to prepare LDHs is often defined as a simple and economically friendly technique. The technique permits direct synthesis of anions with LDHs with a broad range of possible interlayers that range from anions of simple inorganic to anions of complex organic compounds. Additionally, the quantity of synthesized LDHs could be scaled up or down.

To synthesize LDHs using the co-precipitation method, four fundamental components to be considered are [18]:

- divalent cations, M(II), from a soluble source to produce the layers,

- trivalent cations, $\mathrm{M}(\mathrm{III})$, from a soluble source to produce the layers,

- materials for the interlayer anions commonly in the form of soluble ionic compounds; sodium carbonate is used if carbonate is the desired outcome, and conversely for sodium nitrate,

- a strong base that is capable to precipitate the LDHs. The most suitable bases are sodium hydroxide, potassium hydroxide, ammonia, and urea.

\section{ION EXCHANGE METHOD}

While the co-precipitation method is known as the direct method, the ion exchange method is known as the indirect method. The ion exchange method is usually used in the synthesis of LDHs because it is cost-effective. Consequently, a majority of hybrid hydrotalcites are obtained through the ion exchange method from a nitrate or chloride hydrotalcite.

The most common and inexpensive LDHs contain carbonate anion and these LDHs are the most stable. LDHs are more stable when more densely charged carbonate 
a)

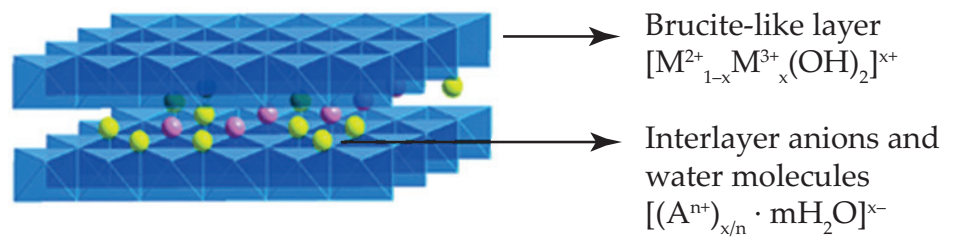

b)

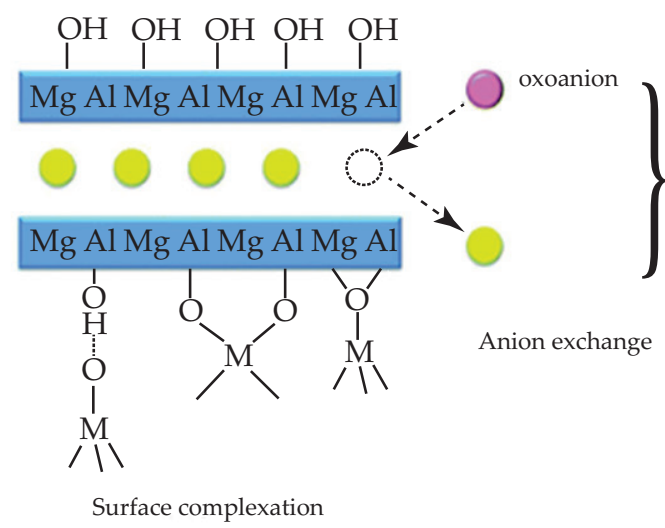

Fig. 3. Mechanism of metal-anion (Mn+) adsorption on LDH [29]

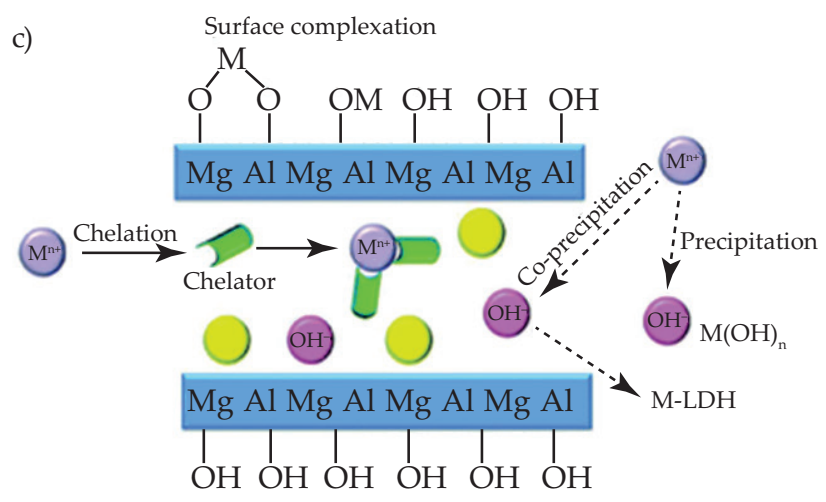

process, cross-linking reaction, and nanoparticle aggregation and coalescence. Figure 4 shows scanning electron microscope (SEM) images of LDHs obtained from the solgel method. When comparing images presented in Fig. 4c and $4 \mathrm{~d}$, the increase observed in thickness is nearly $500 \%$ from NiAl-A to NiAl-5d.

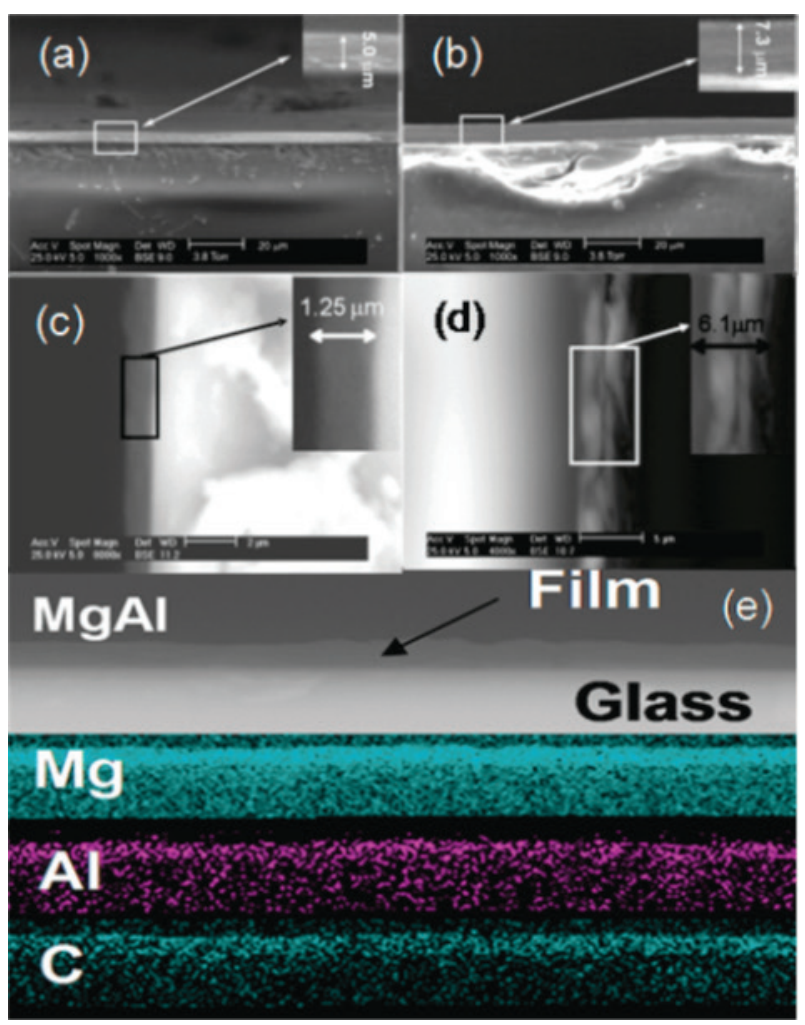

Fig. 4. SEM images of thin films: a) CoNiAl, b) CoNiAl-2d, c) NiAl-A, d) NiAl-A-5d, e) SEM image and corresponding

elemental map of Mg-Al film [36]
The materials obtained in the sol-gel method show controlled pore size and have a high specific surface area. Additionally, LDHs are preferably synthesized through the sol-gel method because they are purer [21]. The reactions taking place during a sol-gel technique occur in alcohol magnesium ethoxide dissolved in hydrochloric acid $(\mathrm{HCl})$ with a solution containing aluminum tri-secbutoxide solutions. The mixture of solutions is heated under reflux condenser while stirring to obtain the gel. The substrate is immersed in the aged sols to control the film thickness. Time plays an important role in the sol-gel method because as the solvent gradually evaporates, the condensation and the cross-linking reactions accelerate. These reactions cause the viscosity of the sol to increase uniformly until it reaches the gelling point [22].

With a mean size of approximately $10 \mu \mathrm{m}$ and an orientation that is parallel to the glass substrate, the LDHs synthesized from the sol-gel method are easily observed. These surface properties are caused by the condensation 


\section{HYDROTHERMAL METHOD}

The synthesis of LDHs through the co-precipitation and sol-gel methods could be optimized using the hydrothermal method because it helps to improve the crystallinity and size of the LDHs crystallites. There are several steps involved to attain the increased particle size of LDHs. First, the metallic salts are dissolved in a solvent before being placed in a stainless-steel reactor. The stainless-steel reactor is then heated with temperatures ranging between $30^{\circ} \mathrm{C}$ to $300^{\circ} \mathrm{C}$ under high pressure and the synthesis time might last several hours or days [23]. The hydrothermal synthesis method involves the use of oxides suspension, hydroxides, or both oxides and hydroxides of $\mathrm{M}^{2+}$ and $\mathrm{M}^{3+}$ cations through the addition of solutions containing acid or salt to the suspension. High temperature and pressure are the conditions necessary for the reaction to occur. There major advantage of the hydrothermal method compared to the co-precipitation method is that it does not produce wastes that might be dangerous to the environment such as $\mathrm{NO}_{3}-\mathrm{Cl}-$, and $\mathrm{OH}-$ [21]. Furthermore, the hydrotalcite content is increased with the increase in temperature and time of synthesis. However, the hydrothermal method is not suitable for industrial implementations because the method requires a large amount of energy to heat the solutions and a long time to complete the synthesis with better results [23].

\section{INDUCED HYDROLYSIS METHOD}

The induced hydrolysis method involves the precipitation of $\mathrm{M}^{3+}$ cation hydroxide at a $\mathrm{pH}$ slightly lower than the $\mathrm{pH}$ of the $\mathrm{M}^{2+}$ cation hydroxides used. The aqueous suspension of $\mathrm{M}^{3+}$ mixed with the $\mathrm{M}^{2+}$ suspension and sodium hydroxide $(\mathrm{NaOH})$ solution is added simultaneously to the mixture to maintain a fixed $\mathrm{pH}$ value [21]. Induced hydrolysis silylation or silane grafting is a series of LDH synthesis processes that utilize the induced hydrolysis method. The method is effective in modifying the surfaces of inorganic materials such as glass and silicon. Examples of the LDHs synthesized using this method are $\mathrm{Mg}_{6} \mathrm{Al}_{2}(\mathrm{OH})_{16} \mathrm{CO}_{3} \cdot 4 \mathrm{H}_{2} \mathrm{O}(\mathrm{Ht})$, Mg-Al-Htd-Sil (Hd-Si), Mg-Al-Htw-Sil (Hw-Si), Mg-Al-Sw-Sil (HSw-Si), and Mg-Al-SDS-APS (HG-Si) [24].

Figure 5 shows the morphologies of some silylated products. Based on the transmission electron microscope (TEM) images, the surface of the small Hd-Si platelets, obtained using dried $\mathrm{Ht}$ in an ethanol medium, is smooth, similar to the raw Ht surface. However, the surface of Hw-Si sample crystals that used rich in water Htw as the substrate exhibited a rough surface. The HSw-Si sample displayed a spherical aggregation with a unique fluffy structure. On the other hand, large, tightly bonded, plate-like particles with rough surfaces were observed for the HG-Si sample. The different reaction media might contribute to the difference in the morphologies of the products.
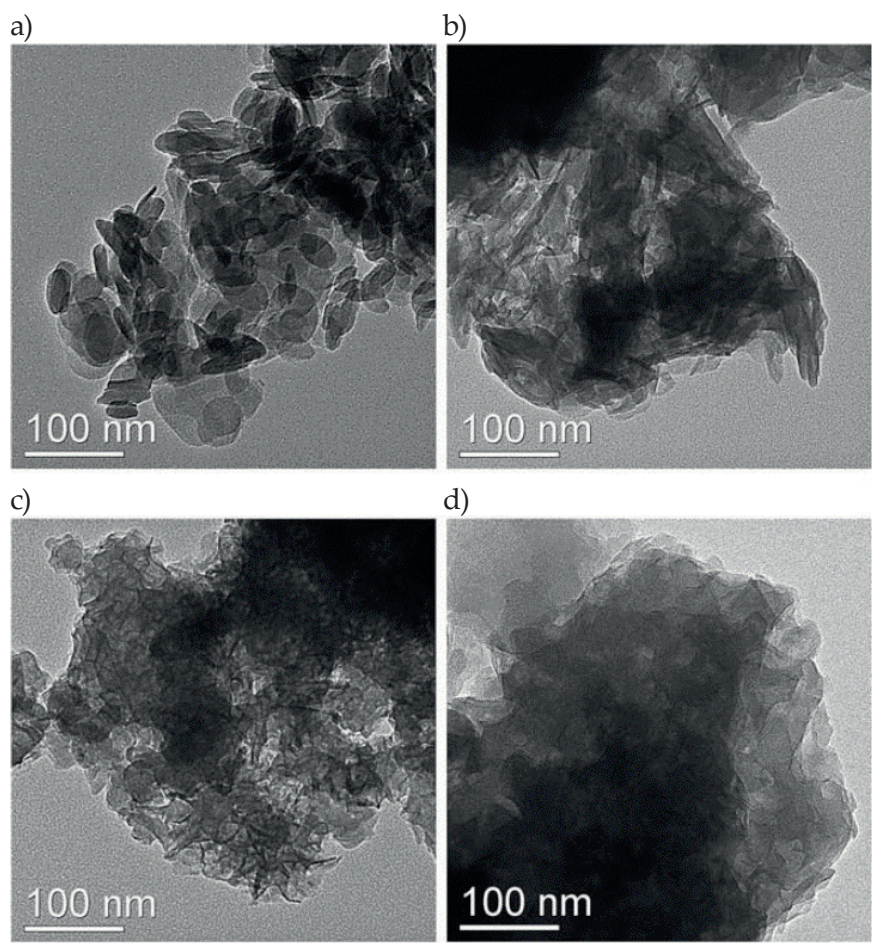

d)

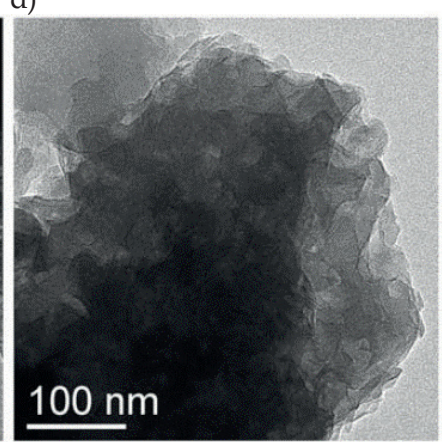

Fig. 5. TEM images of silylated LDHs: a) $\mathrm{Hd}-\mathrm{Si}$, b) $\mathrm{Hw}-\mathrm{Si}$, c) HSw-Si, d) HG-Si

\section{APPLICATION OF LAYERED DOUBLE HYDROXIDES}

\section{Applications in biological and pharmaceutical fields}

Plant-based products have been widely used as medications to treat numerous diseases since a long time ago and the information from a long history of the traditional medicine practice give rise to contemporary medications. Natural resources make up almost $20 \%$ of the pharmaceutical compounds and their by-products that are accessible today. Outstanding properties such as extraordinary chemical diversity, macromolecular specificity in both chemical and biological properties, and less toxicity exhibited by natural products make them more appealing in researches to find novel drugs and develop new-generation drugs such as target-based drugs [25]. However, biocompatibility and toxicity of most natural compounds are the leading causes of natural products not passing the clinical trial phases of new drug development. Furthermore, when large-sized materials are used, natural drugs obtained show vivo instability, poor bioavailability, poor absorption, poor solubility, and problems related to specific-target delivery. To solve this problem, the use of new target-based drug delivery systems that target specific body parts is the only option. Consequently, the development of advanced medications with controlled drug release and delivery properties can only be achieved through the study of nanotechnology [25].

Compared to biomolecules, LDH lattices could withstand harsh environments similar to other layered inorganic materials. LDHs have high adsorption ability, high 
cation exchange capacity, high internal surface area, reactions between the interlayers, and less toxic properties that make them valuable in the biological and pharmaceutical fields [26]. To enhance their stability (safer drug preservation), numerous bio-functionalized molecules such as deoxyribonucleotides, peptides, proteins, and medication were intercalated with LDHs. Additionally, drugs without any structural deformation can still be retrieved through size, morphology, chemical composition, charge density, salt concentration, $\mathrm{pH}$, and surface properties manipulation, therefore the LDHs release profile can be controlled. The manipulation makes it easy for the LDHs to infuse in the plasma membrane, allowing them to transport the biomolecules efficiently to the targeted cells. Since the LDHs' controlled release properties depend on the salt concentration and $\mathrm{pH}$ of the environment that they are in, the biomolecules are often programmed to end in the lysosome, which is slightly acidic and rich in electrolyte [27].

\section{Applications of Ca-Al LDHs in drug delivery systems (DDS)}

The most significant phenomenon within the scope of drug delivery system is the process of drug release. The drug release process encompasses the migration of the drug solutes from their starting point through the delivery system to the external surface and ends at the release medium [26]. LDHs are widely used in drug delivery applications known as the drug delivery systems (DDS). DDS are formulated to alter the pharmacokinetics and the biodistributions of drugs. Furthermore, DDS are utilized as drug reservoirs because of their ability to enhance several crucial properties of "free" drugs such as improving the drug's solubility, in vivo stability, and ability to remove damaged tissues, therefore protecting the drug from degradation [28].

LDHs have explosive growth in the controlled synthesis on the prospects of its usage in clinical therapy especially in their biocompatibility and toxicity of the LDHs and the anticancer drugs that interleaved LDH materials [28]. The possibility of controlling the release of drugs from their interleaved layered materials makes LDHs excellent candidates as delivery hosts in the pharmaceutical field. Therefore, some layered materials are studied as potential hosts in DDS, for example interleaved anticancer agents such as cytarabine [30]. Studies on LDHchitosan hybrid or enteric polymers which have recently developed organic-inorganic nanohybrids based drugs delivery system, showed great biocompatibility, ordered structure and evaded drug leaching.

The applications of Ca-Al LDHs in drug delivery systems were reported in some studies. LDHs were already widely used in anionic drugs DDS due to their biocompatibility and ability to perform anion exchanges. A study reported that $\mathrm{Ca}-\mathrm{Al} \mathrm{LDH}$ were used as vehicles for drug anions because they did not transmit acute cyto-

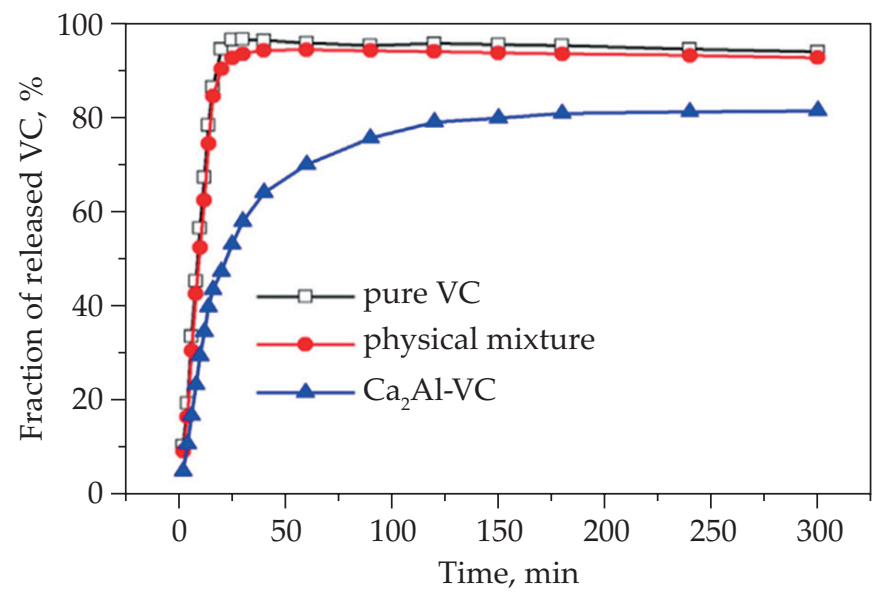

Fig. 6. UV-Vis spectra of three drugs tested in the phosphate buffers at $\mathrm{pH}$ 7.4. Empty square represents pure VC; solid circle represents physical mixture ( $\left.\mathrm{VC}+\mathrm{Ca}_{2} \mathrm{Al}-\mathrm{NO}_{3}\right)$; and solid triangle represents Ca2Al-VC

toxic effects on the human body [31]. In another study, Ca-Al LDHs were tested and proved as able to carry hydroxide-methotrexate (MTX) nanohybrid, an anticancer drug, for an anticancer application. Through the Fickian diffusion mechanism, the study confirmed that the drugs were successfully released at $\mathrm{pH} 7.4$ from the nanoparticle matrix system [32]. Another investigation studied the controlled release of vitamin C (VC) intercalated with $\mathrm{Ca}-\mathrm{Al} \mathrm{LDH}$ by comparing three samples of pure $\mathrm{VC}$, physical mixtures of $\mathrm{VC}$, and $\mathrm{Ca}_{2} \mathrm{Al}^{-\mathrm{NO}_{3}}$ and $\mathrm{Ca}_{2} \mathrm{Al}-\mathrm{VC}$. Each sample was separately tested at $\mathrm{pH} 7.4$ (phosphate buffer) for time intervals of up to 300 minutes. Figure 6 shows the amount of VC released after analyzing the characteristics of the UV-Vis spectra. After 20 minutes, almost $100 \%$ of the VC was released by the pure VC and the physical mixture of $\mathrm{VC}$ and $\mathrm{Ca}_{2} \mathrm{Al}_{-} \mathrm{NO}_{3}$. However, the $\mathrm{VC}$ release time in phosphate buffer was significantly extended when $\mathrm{Ca}_{2} \mathrm{Al}-\mathrm{VC}$ was employed. This proves that after 120 minutes the release of VC had reached equilibrium and was followed by slow release [31].

\section{The use of LDHs in polymer modification}

Furthermore, by not only focusing on the LDHs ability in the controlled release and slow release of drugs in drug delivery systems (DDS), LDHs too are able to act as an important nanofiller in the synthesis of polymer nanocomposite. They are widely known for its ability in improving the stability of heat and flame retardancy of polymer composites [34]. The usage of LDHs as nanofiller for the synthesis of polymer nanocomposites are mainly because of their two core characteristics; numerous intercalating anionic species in their geometry of layered crystalline, plus the interchange ability of interlayer anions with other larger anionic species.

A cone calorimeter test to prove the ability of LDHs in improving the stability of heat and flame retardancy of polymer composites. Cone calorimeter test is used to assess 


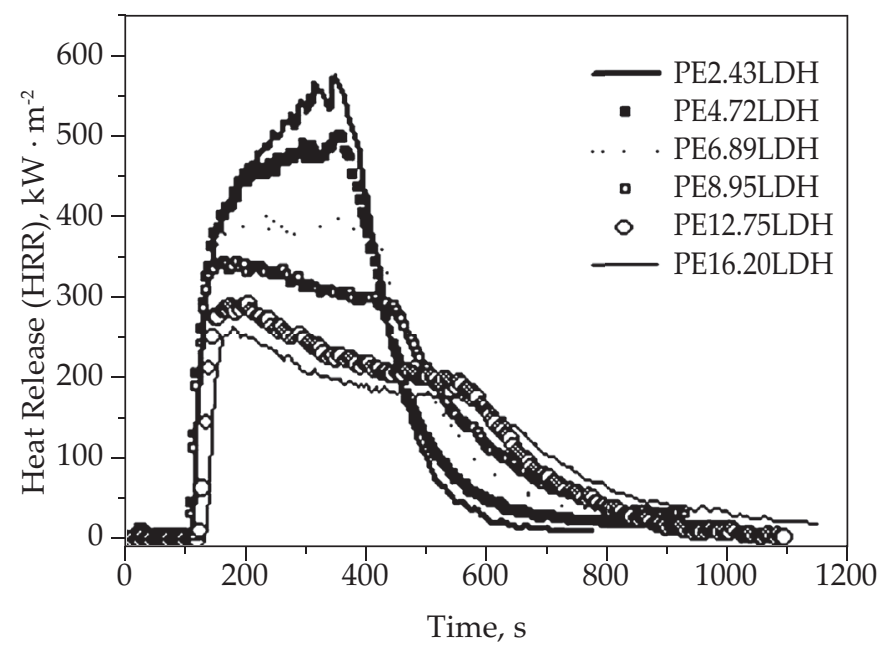

Fig. 7. Graph of variation of heat release rate (HRR) with time

the flammability of a polymetric. The parameter monitored in this test is the heat release rate (HRR), where the oxygen consumed amount during combustion is calculated. HRR represents as a critical variable that shows how quick a fire can reach to an uncontrollable stage, thus providing information on the size and speed of the fire's grow [34].

Figure 7 shows LDHs substantially lowers the peak heat release rate (PHRR) and flattened the HRR curve. Based on the graph shown, as the concentration of LDHs increases, the burning rate of material reduces. Under the external heat flux of $30 \mathrm{kWm}^{-2}$ and $35 \mathrm{kWm}^{-2}$, the cone calorimeter shows a PHRR value of over $600 \mathrm{kWm}^{-2}$ for polyethylene with little amount of LDHs concentration. However, a significant reduction was shown in the PHRR as the concentration of LDHs was increased, from 600 $\mathrm{kWm}^{-2}$ to $500 \mathrm{kWm}^{-2}$. The PHRR lowered to below 300 $\mathrm{kWm}^{-2}$ at much higher LDHs concentration [34]

Moreover, LDHs too are used in improving the thermal stability of polymer composite by observing the thermal decomposition behaviour of polypropylene and flame retardant $(\mathrm{PP} / \mathrm{FR})$-composites under the thermogravimetric analysis (TGA) [35].

Based on Figure 8, polypropylene-composites TG curves are similar to neat polypropylene. By comparing to neat polypropylene, the decomposition temperatures at $50 \%$ mass loss $\left(T_{50}\right)$ and onset decomposition temperatures at $10 \%$ mass loss $\left(T_{10}\right)$ of PP-composites are slightly higher than neat PP. This thus prove that flame retardant (FR) filler used demonstrate a catalysing effect in thermal decomposition thus improving the PP matrix thermal stability [35].

\section{INSTRUMENTS USED TO MEASURE THE EFFICIENCY OF LDHS APPLICATIONS}

\section{Powder X-ray diffraction}

Powder X-ray diffraction (PXRD) is a rapid analytical method to study the structures of crystals, atomic spac-

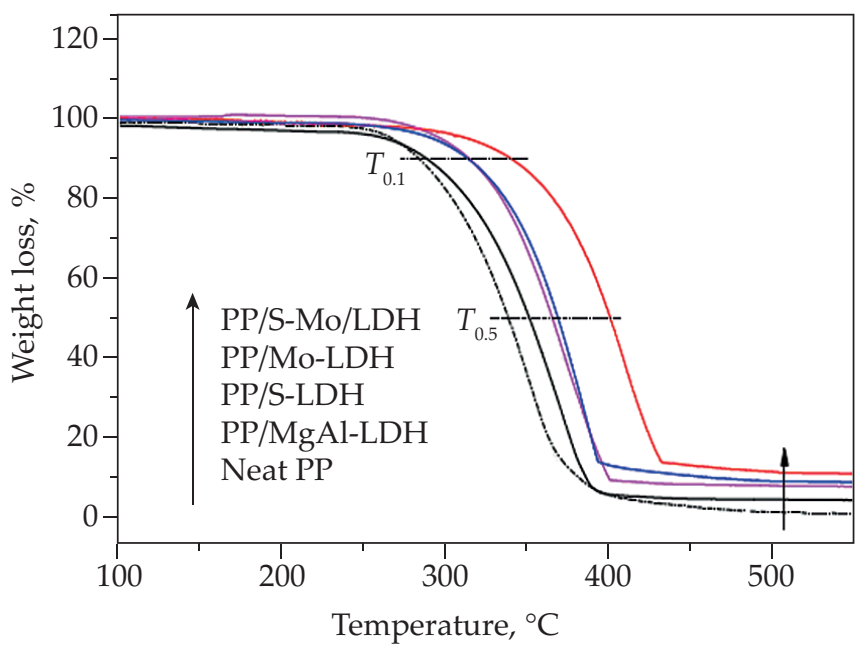

Fig. 8. Graph of percent weight loss with temperature in thermogravimetric analysis (TGA)

ing, and detect the presence of defects in crystal structures. PXRD is used mainly for the determination of the analyzed crystalline materials phase and the method also offers information on the dimensions of the crystalline materials unit cell [36]. The cathode ray tube inside a PXRD generates X-rays which are filtered to form the monochromatic radiation, collimated to concentrate, and directed towards the sample. The conditions satisfy Bragg's Law when the interactions of the incident rays with the sample form constructive interference. The law relates the wavelengths of the electromagnetics to the angle of diffraction and the lattice spacing in the crystalline sample [37]. In this project, the powdered samples of SA-Ca-Al LDHs were analyzed in 2 thetas within the 50 to 70 o range and the step size was 0.03 o while the count time for each point was 2 seconds.

\section{Attenuated total reflectance Fourier transform infrared spectroscopy}

Attenuated total reflectance Fourier transform infrared (ATIR-FTIR) spectroscopy is a tool used to measure the infrared spectra of both liquids and solids. The ATRFTIR spectra can still be obtained without diluting the samples in a matrix such as Nujol oil. To characterize an organic compound, the ATR-FTIR spectroscopy only needs a drop of liquid or a dispersed solid sample on its internal reflection element (IRE) for analysis. The technique utilizes and detects the unique and identifiable spectrum characteristics of most substances because the Fourier transform infrared (FTIR) spectroscopy is able to identify structures of functional groups such as $\mathrm{C}=\mathrm{O}$, $\mathrm{C}-\mathrm{H}$, and $\mathrm{N}-\mathrm{H}$. The beam diffraction is preferred compared to the absorption and reflection beams. This project requires a resolution of $4 \mathrm{~cm}-1$ and a frequency range between 4000 to $450 \mathrm{~cm}-1$. The FTIR technique is favored for the coating analysis because of its simplicity as well as rapid and effective results. Figure 7 shows a spectrum comparison of liquid 4-methyl- 2-pentanol using 


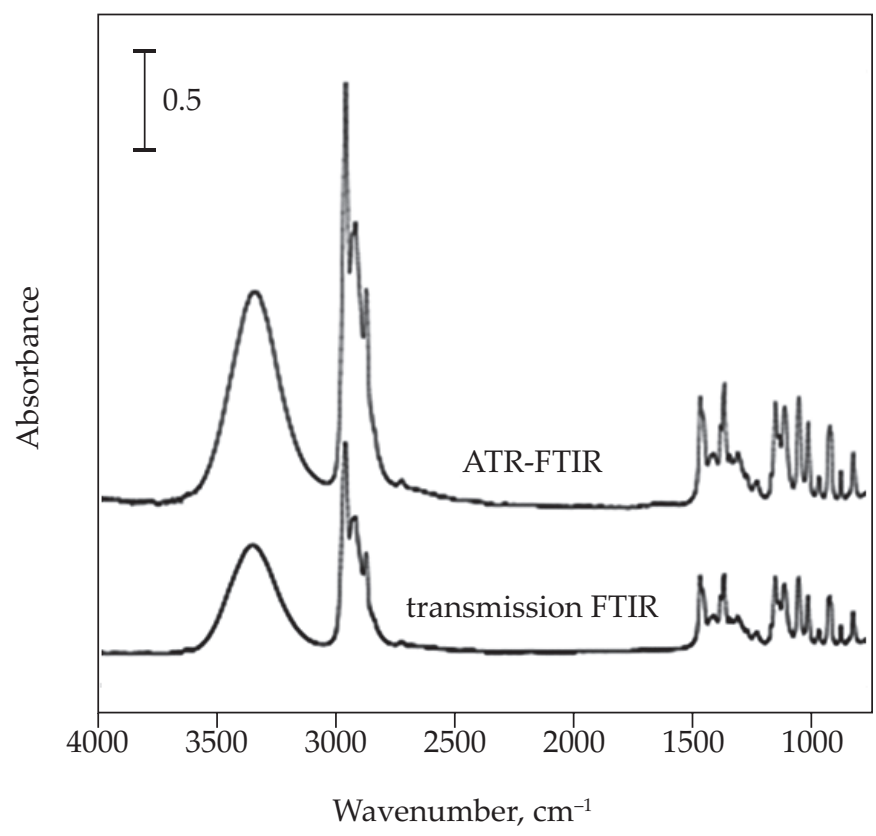

Fig. 9. A comparison of the liquid 4-methyl- 2-pentanol infrared spectrum using ATR-FTIR spectroscopy and transmission FTIR spectroscopy

the ATR-FTIR spectroscopy and transmission FTIR spectroscopy [38].

\section{Carbon hydrogen nitrogen sulfur analyzer}

Carbon hydrogen nitrogen sulfur (CHNS) analyzer is a commercially available analyzer used to analyze carbon, hydrogen, nitrogen, and sulfur in organic substances in solid, liquid, or volatile viscous forms [38]. The CHNS analysis is widely used in various fields including polymers, chemicals, pharmaceuticals, food, and the environment.

\section{Accelerated surface area and porosimetry}

One of the parameters used in the accelerated surface area and porosimetry system is the Breuneur-EmmetTeller (BET) analysis. The BET method was used in characterizing a porous material's surface area through the semi-empirical fitting of the gas-adsorption isotherms [39]. The BET is an extended concept of Langmuir adsorption to multiple molecular layers. The technique measures the phenomenon and correlates it to physical properties such as the total surface area, pore size distribution, micropore analysis, and the porosity of the materials. Most standard BET methods require several milligrams of the dried sample before the analysis of suspended particles and small samples like nanocomposite wet preps [38].

\section{CONCLUSIONS}

This review discussed the synthesis and applications of LDHs. Recent developments in the biological and pharma- ceutical applications of LDH nanoparticles and their role as efficient DDS were also reported. Among the available methods used to synthetize LDH nanoparticles, the ion exchange and hydrothermal methods have proved to be the best. Ion exchange has always been used as an alternative technique whenever the co-precipitation method was used to produce specific anion-pillared LDHs with equivalent specific functions. Additionally, the hydrothermal method avoids producing of wastes that might be dangerous to the environment. However, based on the numerous studies on LDHs as efficient DDS, the best synthesis of LDHs for DDS applications was the co-precipitation method. The observation was supported by the successful release of the intercalated anions from the LDHs.

\section{RECOMMENDATIONS}

The application of controlled release in drug release systems using Ca-Al LDHs could be improved by trying different $\mathrm{pH}$ ranges. The time taken for the drugs to be released in the target cells could also be observed and further studied.

The applications of LDHs, especially Ca-Al LDHs, should not be limited to biological, pharmaceutical, and drug delivery systems but could also include other fields such as environmental and agricultural applications. For instance, LDHs could be used in wastewater treatment to remove anionic pollutants such as heavy metal ions, taking advantage of the high removal efficiency and the environmentally friendly properties of the LDHs.

Additionally, the applications of the LDHs to reduce the environmental effects caused by the fossil fuels depletion and in the controlled release of herbicides in agriculture that employs Ca-Al LDHs through various methods for a better environment could be further investigated.

\section{ACKNOWLEDGEMENTS}

The support from Universiti Teknologi MARA (UiTM) and the Ministry of Education (MOE) are highly acknowledged and appreciated. The authors would like to accredit the financial support from the MOE through the Fundamental Research Grant Scheme [600-IRMI/FRGS 5/3 (112/2019)].

\section{REFERENCES}

[1] Okpala C.C.: European Polymer Journal 2013, 8(11), 17.

[2] George R.: Journal of Dentistry and Oral Biosciences 2011, 2(3), 38. https://doi.org/10.5368/JDOB/2011.2.3.3.2

[3] Bini M., Monteforte F.: Journal of Analytical and Pharmaceutical Research 2018, 7(3), 00206. https://doi.org/10.15406/japlr.2018.07.00206

[4] Mishra G., Dash B., Pandey S.: Applied Clay Sciences 2018, 153, 172. https://doi.org/10.1016/j.clay.2017.12.021

[5] Arrabito G., Bonasera A., Prestopino G. et al.: Crystals 2019, 9(7), 361. 
https://doi.org/10.3390/cryst9070361

[6] Barahuie F., Hussein M.Z., Fakurazi S., Zainal Z.: International Journal of Molecular Sciences 2014, 15(5), 7750 .

https://doi.org/10.3390/ijms15057750

[7] Schöllhorn R.: Physica B+C 1980, 99, 89 .

https://doi.org/10.1016/0378-4363(80)90214-4

[8] Shafiei S.S., Solati-Hashjin M,. Rahim-Zadeh H., Samadikuchaksaraei A.: Advances in Applied Ceramics 2013, 112(1), 59. https://doi.org/10.1179/1743676112Y.0000000045

[9] Khan A.I., O'Hare D.: Journal of Materials Chemistry 2002, 12(11), 3191. https://doi.org/10.1039/B204076J

[10] Wang H., Duan W., Wu Y. et al.: Inorganica Chimica Acta 2014, 418, 163. https://doi.org/10.1016/j.ica.2014.04.031

[11] Baig N., Sajid M.: Trends in Environmental Analytical Chemistry 2017, 16, 1. https://doi.org/10.1016/j.teac.2017.10.003

[12] Pradhan S., Costa F.R., Wagenknecht U. et al.: European Polymer Journal 2008, 44(10), 3122. https://doi.org/10.1016/j.eurpolymj.2008.07.025

[13] Jaiswal A., Gautam R.K., Chattopadhyaya M.C.: Advanced Materials for Agriculture, Food, and Environmental Safety 2014, 11, 1. https://doi.org/10.1002/9781118773857.ch1

[14] Ahmad R., Hussein M.Z., Sarijo S.H. et al: Journal of Materials 2016, 2016, 1285721. https://doi.org/10.1155/2016/1285721

[15] Saha S., Ray S., Ghosh S., Chakraborty J.: Journal of the American Ceramic Society 2018, 101(9), 3924. https://doi.org/10.1111/jace.15555

[16] Nagaraj V.J., Sun X., Mehta J. et al.: Journal of Nanotechnology 2015, 1, 2015. https://doi.org/10.1155/2015/350370

[17] Wijitwongwan R.P., Intasa-ard S.G., Ogawa M.: ChemEngineering 2019, 3(3), 68. https://doi.org/10.3390/chemengineering3030068

[18] Theiss F.L., Ayoko G.A., Frost R.L.: Applied Surface Science 2016, 383, 200. https://doi.org/10.1016/j.apsusc.2016.04.150

[19] Palin L., Milanesio M., van Beek W., Conterosito E.: Journal of Nanomaterials 2019, 1, 2019. https://doi.org/10.1155/2019/4612493

[20] Kaitao L., Guirong W.A., Dianqing L.I. et al.: Chinese Journal of Chemical Engineering 2013, 21(4), 453. https://doi.org/10.1016/S1004-9541(13)60482-6

[21] Benício L.P., Silva R.A., Lopes J.A. et al.: Revista Brasileira de Ciência do Solo 2015, 39(1), 1. https://doi.org/10.1590/01000683rbcs2015081

[22] Prince J., Montoya A,. Ferrat G., Valente J.S.: Chemistry of Materials 2009, 21(24), 5826.

https://doi.org/10.1021/cm902741c
[23] Chaillot D., Bennici S., Brendlé J.: Environmental Science and Pollution Research International 2020, 28, 24375. https://doi.org/10.1007/s11356-020-08498-6

[24] Tao Q., Zhu J., Wellard R.M. et al.: Journal of Materials Chemistry 2011, 21(29), 10711. https://doi.org/10.1039/C1JM10328H

[25] Patra J.K., Das G., Fraceto L.F. et al.: Journal of Nanobiotechnology 2018, 16(1), 71. https://doi.org/10.1186/s12951-018-0392-8

[26] Shahabadi N., Razlansari M.: Journal of Nanoanalysis 2018, 5(4), 210. https://doi.org/10.22034/jna.2018.545418

[27] Choy J.H., Oh J.M., Choi S.J.: Comprehensive Biomaterials 2011, 4, 545. https://doi.org/10.1016/b978-0-08-055294-1.00142-2

[28] Bi X., Zhang H., Dou L.: Pharmaceutics 2014, 6(2), 298. https://doi.org/10.3390/pharmaceutics6020298

[29] Li B., He J., Evans D.G., Duan X.: Applied Clay Science 2004, 27, 199. https://doi.org/10.1016/j.clay.2004.07.002

[30] Gao X., Chen L., Xie J. et al.: Materials Science and Engineering: C 2014, 39, 56. https://doi.org/10.1016/j.msec.2014.02.028

[31] Chakraborty M., Mitra M.K., Chakraborty J.: Bulletin of Materials Science 2017, 40(6), 1203. https://doi.org/10.1007/s12034-017-1468-z

[32] Clark C.M., Barbara L.D.: "Single-crystal X-ray Diffraction".

https://serc.carleton.edu/research_education/geochemsheets/techniques/SXD.html

[33] Schuttlefield J.D., Grassian V.H.: Journal of Chemical Education 2008, 85(2), 279. https://doi.org/10.1021/ed085p279

[34] Costa F.R., Saphiannikova M., Wagenknecht U., Heinrich G.: Wax Crystal Control, Nanocomposites, Stimuli-Responsive Polymers 2007, 210, 101. https://doi.org/10.1007/12_2007_123

[35] Jin L., Huang Q.J., Zeng H.Y. et al.: Composites Part A: Applied Science and Manufacturing 2020, 129, 105717. https://doi.org/10.1016/j.compositesa.2019.105717

[36] Ferreira L.S., Trierweiler J.O.: IFAC Proceedings Volumes 2009, 42(11), 405. https://doi.org/10.3182/20090712-4-TR-2008.00064

[37] Brame J.A., Griggs C.S.: "Surface area analysis using the Brunauer-Emmett-Teller (BET) Method. Sscientific Operation Procedure Series: SOP-C. https://usace.contentdm.oclc.org/digital/collection/ p266001coll1/id/3767/

[38] Fadeeva V.P., Tikhova V.D., Nikulicheva O.N.: Journal of Analytical Chemistry 2008, 63(11), 1094. https://doi.org/10.1134/S1061934808110142

[39] Chem J. M., Tao Q., Zhu J. et al.: Journals of Materials Chemistry 2011, 29, 10711. https://doi.org/10.1039/C1JM10328H

Received 10 X 2021 